\title{
STUDIES ON ECONOMIC TRAITS IN SUCCESSIVE GENERATIONS OF SELFING IN SUGARCANE (SACCHARUM SPP.)
}

\author{
A. Anna Durai*, G.Hemaprabha, V.Raffee Viola, T.S. Sarath Padmanaban and \\ K. Lakshmi
}

\begin{abstract}
Selfing is one of the classical methods with demonstrated merits to understand parental worthiness, achieving homozygosity and for removing the deleterious genes from the genome. The selfed progenies of $\mathrm{S}_{1}, \mathrm{~S}_{2}$ and $\mathrm{S}_{3}$ generation of sugarcane clones viz., Co 775, Co 99008, Co 0304, Co 2000-10, Co 0112 and MS 68/47 and $\mathrm{S}_{6}$ and $\mathrm{S}_{7}$ progenies of Co 1148 were studied for homozygosity in successive generations of selfing, level of inbreeding depression and transgressive segregation for important economic traits. A narrow level of variation for HR Brix and wide variation for number of millable canes and moderate level of variation for cane thickness was observed in $\mathrm{S}_{1} \mathrm{~S}_{2}$ and $\mathrm{S}_{3}$ generations. The genotypes with least variation among the selfed progenies in preceding generation of selfing did not show the same response in succeeding generations of selfing indicating that the genotypes behave differently in successive generations of selfing during the process of attaining homozygosity. The inbreeding individuals of 1148-13-11-2-237 and 1148-S4-247 depicted the least variation for the traits studied in later generations of selfing. Some of the inbreeding individuals from early generation of selfing of Co 775, MS 68/47, and Co 0112 for number of millable canes, Co 99008, MS 68/47 and Co 0112 for HR Brix and MS 68/47, Co 0112 for cane thickness surpassed their respective parents in their performance. HR Brix was the only trait which was least affected by inbreeding depression and greater level of inbreeding depression was observed for cane thickness. Though inbreeding was observed in early generation of selfing for number of millable canes, no inbreeding depression was observed for the trait in succeeding generations of selfing. Inbreds with higher level of homozygosity in the later generation of selfings viz., $\mathrm{S}_{6}-2-59$ and $\mathrm{S}_{6}-2-60, \mathrm{~S}_{6}-2-63$ and $\mathrm{S}_{6}-2-73$ and $\mathrm{S}_{6}-2-66$ and $\mathrm{S}_{6}-2-69$ of Co 1148 developed in this study may be utilized for hybrid seed production in sugarcane.
\end{abstract}

Keywords: sugarcane, self, variation, homozygosity, inbreeding depression, transgressive segregation

\section{Introduction}

The present-day sugarcane is a derivative of different species of Saccharum complex and related genera and hence was considered as to have wider genetic base than other crop plants (Roach and Daniels, 1987). Among the different methods of breeding crop plants, selfing is the most intense form of inbreeding (Mettler and Gregg, 1973). In sugarcane, level of selfing was reported to be in the range of $0-80 \%$ depending on the specific cross combination, the direction of the crossing (Hogarth, 1980), pollen fertility and self-incompatibility mechanism operating within the parents. Saccharum officinarum though a polyploidy, predominantly formed bivalents at meiosis and the large number of seedlings were obtained on selfing indicating that there was no incompatibility system operative resulting in self-sterility. In case of Saccharum spontaneum which is also highly self-fertile, no loss of vigour was observed on selfing but superior types were obtained (Babu and Ethirajan 1962). Panje and

A. Anna Durai, G.Hemaprabha, V.Raffee Viola, T.S. Sarath Padmanaban and K. Lakshmi

ICAR-Sugarcane Breeding Institute, Coimbatore-641 007, Tamil Nadu, India.

*Corresponding author: ayyadu@gmail.com

Submitted: 2 November 2019; Accepted: 14 February 2020 
Ethirajan (1959) studied inbreeding in Saccharum spantaneum with various forms from India and some of the clones from Spontaneum Expedition Scheme (SES) collection and remarked that most striking feature in the selfed progenies was no loss of vigour as a result of the inbreeding. Similar to the basic species, inter-specific hybrids also performed well the inbreeding without loss of vigour in the progeny. Stevenson (1953) demonstrated that some population derived from inbreeding the inter-specific hybrids did not show any appreciable loss of vigour and they behaved like wild ancestors. Self-pollination did not produce a general loss in yield traits such as soluble acids, stalk number and stalk diameter (Silva and Goncalves 2011).

Inbreeding has been used as method of sugarcane improvement in many ways and it is one of the classical methods to understand the potential worthiness of parents. Selfing exposes and eliminates the deleterious alleles in commercial breeding clones and rapidly concentrates the genes for sugar content. In some populations from selfed S.spontaneum derivatives, there were distinct improvements over the parents in sucrose content of juice and later it was concluded that inbred derivatives with appreciable improvement in juice quality could be produced by successive selfing of certain forms of S.spontaneum and such selfed derivatives were selected as basic material for progressive inbreeding programme (Stevenson, 1965). Ethirajan et al. (1978) recognized the potential present in the inbred selection to establish a gene pool for breeding of high quality sugarcane. Further Cassalet et al. (1996) mentioned that it is possible to segregate different traits in a particular variety without vigor losses by means of selfing and identify disease free plants from susceptible parents. Ferreira et al. (2005) in their study on effects of inbreeding and selection of clones in families obtained through bi-parental, polycrossings and selfing suggested an alternative form of using $\mathrm{S}_{1}$ clones as donors in the breeding process of reciprocal recurrent selection. The seedling population in which one or both parents were inbreds gave an overall selection percentage at the field nursery stage higher than those populations in general programme. Clonal evaluation of selfs of commercial varieties indicated an improvement in sucrose content with successive cycles of selfing (Shanthi and Alarmelu 2011). Inbreeding also created required variation and helps in exploiting additive genetic variance in the complex polyploidy genome of sugarcane (Durai and Hemaprabha 2016). This method of breeding is being utilized in identifying 22 Coimbatore canes (Co canes) including the recently identified Co 15002 (polycross derivative of self of Co 1148), genetic stock (SBI 1148-1113-2-255) and commercial varieties like CoLk 94184 (self of CoLK 8001) in India.

The production of inbreds and their use in hybrid production is well demonstrated in cross pollinated diploid crop like maize. Though inbreeding approach in the complex polyploidy genome of sugarcane has been considered as controversial, superior genotypes can be obtained through self-pollination. Repeated selfing of sugarcane clones for few generations guided by molecular marker profiling and progeny testing is one of the approaches to develop inbreds and identifying homozygous individuals (Ram et al. 2015). Development of homozygous parental lines with good combining ability is important to develop heterotic hybrids in sugarcane with high yield, quality and resistance to major stresses that can be directly used in commercial planting. The isozyme analysis of hybrid clone and inbred derivatives have shown a higher level of genetic similarity of inbreds in contrast to the respective parental clones indicating that the level of heterozygosity in this complex polyploidy crop 
could be lowered by selfing (Hemaprabha et al. 2003). Parental potential was assessed through selfing by a criterion that a good parent for quality improvement would be one that generated selfs with high mean, low SD and narrow range (Hemaprabha and Singh 2007).

Considering the potential worthiness of inbreeding and the current research to identify homogenous lines in sugarcane, present study was conducted in the modern sugarcane varieties i.e. interspecific hybrids with the objectives to estimate the level of variation in different inbreeding populations of sugarcane viz., $\mathrm{S}_{1}, \mathrm{~S}_{2}, \mathrm{~S}_{3}, \mathrm{~S}_{6}$ and $\mathrm{S}_{7}$ in order to explore the possibilities of getting relatively homogenous inbreds on repeated selfing which can be used further in sugarcane hybrid seed production and to quantify the inbreeding depression / transgressive segregation among the traits of breeding importance over different generations of selfing.

\section{Materials and Methods}

Breeding material of the present study comprised six parents viz., Co 775, Co 99008, Co 0304, Co 2000-10, Co 0112 and MS 6847. The selfing cycle was initiated with selfing of parents during the year 2008 and a total of $350 \mathrm{~S}_{1}$ inbreeding individuals were developed which were forwarded from ground nursery to clonal stage. Among the $\mathrm{S}_{1}$ inbreeding population, nine flowering selfs (99008-91, 99008-113, 775-21, 775-22, 775-27, $775-28,775-45,0304-127$ and ms68/47-3) with more than $20 \%$ pollen fertility were further selfed to obtain $457 \mathrm{~S}_{2}$ populations. These $\mathrm{S}_{2}$ population of Co 775 (775-27-311 and 775-45-406) and MS 68/47 (ms 68/47 -3-12) were selfed to get $\mathrm{S}_{3}$ individuals which were carried to the clonal stage. Similarly the clones 1148-13-11-237, 1148$13-11-2-252, \quad 1148-\mathrm{S}_{4}-242-5$ and $1148-\mathrm{S}_{4} 242-$ 7 were selfed to get four $\mathrm{S}_{6}$ inbreeding families of 185 individuals. Further eight inbreeding individuals viz., 1148-13-11-2-237-69, 1148-1311-2-252-15, 1148-13-11-2-252-47, 1148-13-11$2-252-55,1148-\mathrm{S}_{4}-242-5-54,1148-\mathrm{S}_{4}-242-7-118$, $1148-\mathrm{S}_{4}-242-7-146, \quad 1148-\mathrm{S}_{4}-242-7-121$ in $\mathrm{S}_{6}$ generation were selfed to get $173 \mathrm{~S}_{7}$ inbreeding individuals. All the inbreeding individuals in clonal stage were evaluated during 2016-17 in a single row trial of plot size of $5.4 \mathrm{~m}^{2}(1 \mathrm{r} \times 6 \mathrm{~m}$ $\mathrm{x} 0.9 \mathrm{~m}$ ) and the parents were replicated in each block. Inbreeding populations were studied along with their respective parents for three important economic traits viz., number of millable canes (NMC), cane thickness (CT) and HR Brix.

Standard statistical techniques were followed to estimate different parameters of variation. Inbreeding depression / transgressive segregation was estimated as per the following formula.

Inbreeding depression $(\mathrm{IBD}) \%=\left(\mathrm{F}_{1}-\mathrm{F}_{2}\right) / \mathrm{F}_{1} \times 100$ where

$\mathrm{F}_{1}=$ Mean of the clone I (parental performance)

$\mathrm{F}_{2}=$ Mean of the generation of clone I (progeny performance)

For molecular analysis of advanced generation inbreds for their homozygosity, plant sample was collected from eleven $\mathrm{S}_{7}$ selfed progenies viz., $1148-\mathrm{S}_{6}-2-59,1148-\mathrm{S}_{6}-2-60,1148-\mathrm{S}_{6}-61,1148-$ $\mathrm{S}_{6}-63,1148-\mathrm{S}_{6}-2-66,1148-\mathrm{S}_{6}-2-69,1148-\mathrm{S}_{6}-2-73$, $1148-\mathrm{S}_{6}-81,1148-\mathrm{S}_{6}-82,1148-\mathrm{S}_{6}-88$ and $1148-\mathrm{S}_{6}-$ 89 along with their immediate parent $1148-\mathrm{S}_{6}-2$ and the grandparent Co 1148. DNA was isolated from young leaf tissue by C-TAB method (Doyle et al. 1987) and purified. The quantity and quality were checked using Nanodrop Spectrophotometer (ND-1000). PCR reaction was carried out with a total volume of $10 \mu \mathrm{l}$ reaction mix consisting final concentration of $20 \mathrm{ng}$ template DNA, 25 pmol each of forward and reverse primers, 0.3unit Taq polymerase (Merck, India), 1x Taq Buffer (Merck, India) and $100 \mu \mathrm{M}$ dNTPs (Merck, India). 
The PCR cycles consisted of 2 minutes at $95^{\circ} \mathrm{C}$ followed by 30 cycles of 1 minute at $94^{\circ} \mathrm{C}, 40$ seconds at the annealing temperature standardized for each primer (ranging from $55^{\circ} \mathrm{C}$ to $58^{\circ} \mathrm{C}$ ), 40 seconds extension at $72^{\circ} \mathrm{C}$ and a final extension of 7 minutes at $72^{\circ} \mathrm{C}$. The PCR reaction was performed in a thermal cycler (Mastercycler Pro S, Eppendorf, Germany) The amplified products of microsatellite analysis were separated on 8 per cent denaturing polyacrylamide gels and micro satellite bands were resolved by silver staining procedures.

For molecular data analysis the amplified bands were scored for presence (1) or absence (0) in all inbreds used and the data were used to calculate the Jaccard's similarity coefficient

\section{List of Primers used}

\begin{tabular}{|l|l|l|c|}
\hline Primers & Forward primer( $\left.5^{\prime}---3^{\prime}\right)$ & Reverse $\operatorname{primer}\left(5^{\prime}---3^{\prime}\right)$ & Temp \\
\hline NKS1 & TGGCATGTGTCATAGCCAAT & CCCCAACTGGGACTTTTACA & 58 \\
\hline NKS3 & CGTGTTCCTCTTCAACAACG & TGCTTCGCTATATATGGGTTCA & 58 \\
\hline NKS8 & GTGACAGCGGCTTGTTCAG & TTAAACACGCAGCCATTCAG & 58 \\
\hline NKS9 & CTTTCAGTGGCCATCTCCAT & GAATGCGCAGGGATAGGATA & 58 \\
\hline NKS31 & AACCACCACTCATCGTCCTC & CACCGAGTTCCCATTGTTCT & 58 \\
\hline NKS34 & CGTCTTGTGGATTGGATTGG & TGGATTGCTCAGGTGTTTCA & 58 \\
\hline NKS57 & CGAGCCTCCCTCCATAGATT & ACCACCACCAACCTCATCTC & 55 \\
\hline NKS61 & TTGGACATGGCAAGTCTTTG & AGGAACCTCCCAAGAACACA & 55 \\
\hline
\end{tabular}

(JSCs) using NTSYS- pc software (Version 2.0). Using molecular marker data, degree of dissimilarity between two genotypes, as the direct description of allelic variation was derived as per Nei and Li (1979). Genetic similarity (GS) that represents the proportion of molecular markers common between the two individuals being compared was performed by comparing the number of rows of marker fragments of (apparently) similar size separated by electrophoresis. Genetic distances between each pair of lines were estimated as $\mathrm{D}=1$ GS. For genetic diversity analysis, Jaccard's coefficient (Jaccard 1908) was used considering it appropriateness with when using a co-dominant marker like SSR. The pair wise Jaccard index is calculated by the following equation: $\mathrm{GSij}=\mathrm{Nij}$ / $[\mathrm{Ni}+\mathrm{Nj}+\mathrm{Nij}]$ where $\mathrm{Nij}$ is the total number of bands common to lines $\mathrm{i}$ and $\mathrm{j}$, and $\mathrm{Ni}$ and $\mathrm{Nj}$ are the number of bands only present in $\mathrm{i}$ and $\mathrm{j}$, respectively.

\section{Results and Discussion}

The various economic traits viz., NMC,CT and HR Brix were affected differently in the selfed progenies and hence these selfed progenies exhibited dissimilar level of variation (Fig. 1) and some of them showed increased improvement over parental clones. Among the three characters studied, very narrow level of variation was observed for HR Brix in the selfed progenies of Co 775. Almost a similar trend was noticed in all $\mathrm{S}_{1}$ progenies of other genotypes and also in $\mathrm{S}_{2}$ and $\mathrm{S}_{3}$ generations. Narrow range observed for HR Brix may be due to the fact that sucrose content in sugarcane is additive in nature and highly heritable with relatively lesser level of environmental effects. Ethirajan et al. (1978) also reported greater phenotypic stability for sucrose content among the selfed progenies of Co 775, Co 1148, CP 44-101, NCo 310, Co 285 and Co 312. NMC recorded wide variation and for cane thickness moderate level of variation were observed. Though the genotypes 
Table 1. Co-efficient of variation observed in early generation inbreds

\begin{tabular}{|c|c|c|c|c|c|c|}
\hline Characters & & $S_{1}$ & S & & & \\
\hline Number of millable & 0.66 & 0.80 & 0.49 & 0.65 & 0.49 & 0.63 \\
\hline canes & Co 99008 & Co $2000-10$ & 0304-127 & $775-27$ & $775-27-311$ & $68 / 47-3-12$ \\
\hline (NMC) & & & & & & \\
\hline Cane thickness & 0.16 & 0.63 & 0.14 & 0.53 & 0.11 & 0.48 \\
\hline & Co $2000-10$ & Co 0112 & 99008-91 & $775-27$ & $775-45-406$ & $68 / 47-3-12$ \\
\hline H.R. brix & 0.10 & 0.19 & 0.09 & 0.17 & 0.07 & 0.16 \\
\hline & Co 775 & MS 68/47 & $\begin{array}{l}99008-91 \\
\text { and } 99008 \text {. } \\
113\end{array}$ & $775-27$ & $775-45-406$ & $775-27-311$ \\
\hline
\end{tabular}

differed in their selfing ability, they produced progenies in identical manner. These results were in agreement with Durai et al. (2012) wherein it was observed that high level of genetic similarity among the parents may be due to the repeated use of few set of parents in developing varieties which are themselves related as parents.

The co-efficient of variation in $\mathrm{S}_{1}$ for $\mathrm{NMC}$ ranged from 0.66 (self of of Co 99008) to 0.80 ( $\mathrm{S}_{1}$ selfs of Co 2000-10). The variation in $\mathrm{S}_{2}$ for this cane character varied from 0.49 (selfs of 0304-127) to 0.65 (selfs of 775-27). In $\mathrm{S}_{3}$ it varied from 0.49 (selfs of 775-27-311) to 0.63 (selfs of 68/47-3-12). The co-efficient of variation for CT varied from 0.16 (selfs of Co 2000-10) to 0.63 (selfs of Co 0112) in $\mathrm{S}_{1}$ and ranged from 0.14 (selfs of 9900891) to 0.53 (selfs of 775-27) in $S_{2}$. The variation

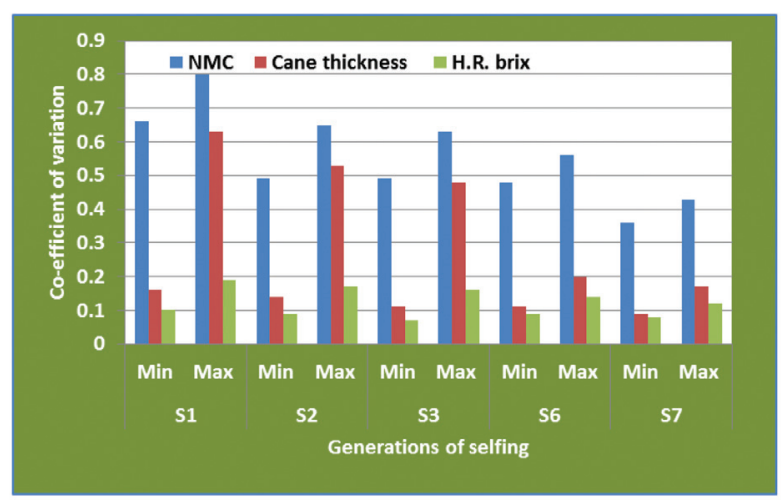

Fig. 1. Trend of variation in the different generations of inbred populations in $\mathrm{S}_{3}$ for CT was in the range of 0.11 (selfs of 775-45-406) to 0.48 (selfs of 68/47-3-12). The co-efficient of variation for HR Brix was found between 0.10 (selfs of Co 775) and 0.19 (selfs of MS 68/47) in $\mathrm{S}_{1}$ and it ranged from 0.09 (selfs of 99008-113 and 99008-91) to 0.17 (selfs of 77527) in $S_{2}$. The variation in $S_{3}$ for HR Brix was in between 0.07 (selfs of 775-45-406) and 0.16 (selfs of 775-27-311). (Table 1).

The range of variation in $\mathrm{S}_{6}$ for NMC was from 0.48 (1148-13-11-2-237) to 0.56 (1148-S $-242-7)$. This was reduced to 0.36 (1148-13-11-2-252-47) to 0.43 (1148- $\left.\mathrm{S}_{4}-242-7-118\right)$ in $\mathrm{S}_{7}$. As observed in the case of $\mathrm{NMC}$, the variation for $\mathrm{CT}$ reduced from $\mathrm{S}_{6}\left(0.11\right.$ in $1148-\mathrm{S}_{4}-242-7$ to 0.20 in 1148 - 13 11-2-252) to $\mathrm{S}_{7}$ (0.09 in 1148-13-11-2-237-29 to 0.17 in 1148-13-11-2-252-47). The $\mathrm{S}_{6}$ inbreeding individuals of 148-13-11-2-237 showed the lowest level of variation for HR Brix (0.09) and among them 1148-S $-242-7$ showed the highest level of variation $(0.14)$. This variation was reduced to the range of 0.08 (1148-S $-242-7-121)$ to 0.12 (114813-11-2-252-47) in $\mathrm{S}_{7}$ (Table 2).

The genotypes exhibiting the least variation in $\mathrm{S}_{1}$ did not show-lowest variation in $\mathrm{S}_{2}$ and $\mathrm{S}_{3}$ which indicated the fact that the different genotypes behave differently in attaining the homozygosity on selfing. Among the different Co canes studied, Co 99008 for NMC, Co 2000-10 for CT and Co 
Table 2. Co-efficient of variation observed in later generation inbreds

\begin{tabular}{lllll}
\hline Characters & $\mathbf{S}_{6}$ & & $\mathbf{S}_{7}$ & \\
\hline NMC & 0.48 & 0.56 & 0.36 & 0.43 \\
& $1148-13-11-2-237$ & $1148-S 4-242-7$ & $1148-13-11-2-252-47$ & $1148-S 4-242-7-118$ \\
Cane & 0.11 & 0.20 & 0.09 & 0.17 \\
thickness & $1148-\mathrm{S} 4-242-7$ & $1148-13-11-2-252$ & $1148-13-11-2-237-29$ & $1148-13-11-2-252-47$ \\
H.R. brix & 0.09 & 0.14 & 0.08 & 0.12 \\
& $1148-13-11-2-237$ & $1148-\mathrm{S} 4-242-7$ & $1148-\mathrm{S} 4-242-7-121$ & $1148-13-11-2-252-47$ \\
\hline
\end{tabular}

775 for HR Brix had the least variation among 0304-127 in $\mathrm{S}_{1}$ and 775-27-311 in $\mathrm{S}_{2}$ 1148-13-11their selfed progenies for the respective traits and 2-237 in $\mathrm{S}_{6}$ and 1148-13-11-2-252-47-1 in $\mathrm{S}_{7}$ for may be considered for developing homogenous inbred population. Thirteen inbreeding individuals NMC and 99008-91 in $\mathrm{S}_{1}$ and 775-45-406 in $\mathrm{S}_{2}$, $1148-S_{4}-242-7$ in $S_{5}$ and $1148-13-11-2-227-S_{6}-1$ in

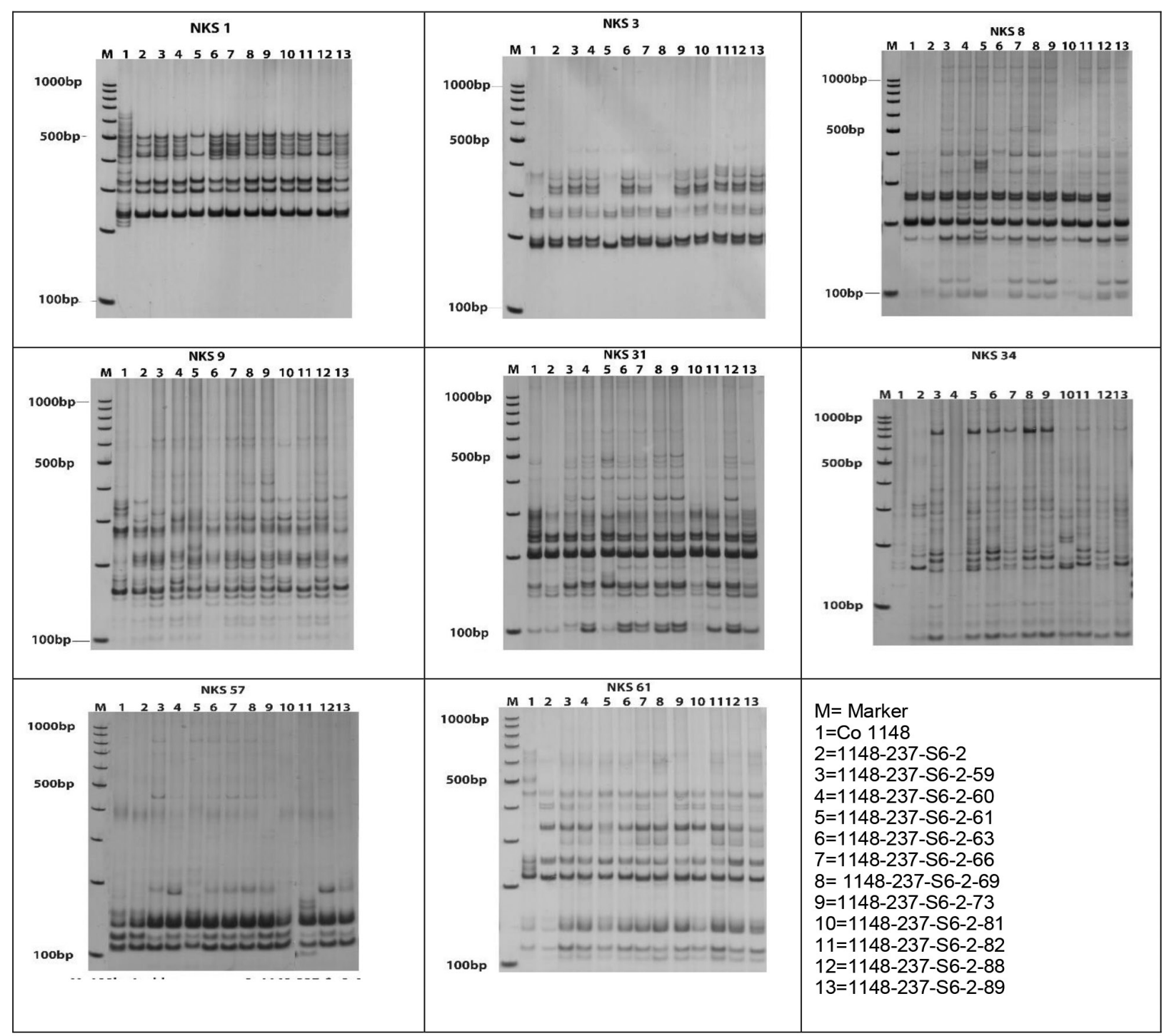

Plate 1. Molecular variation in later generation inbred progenies of Co 1148 


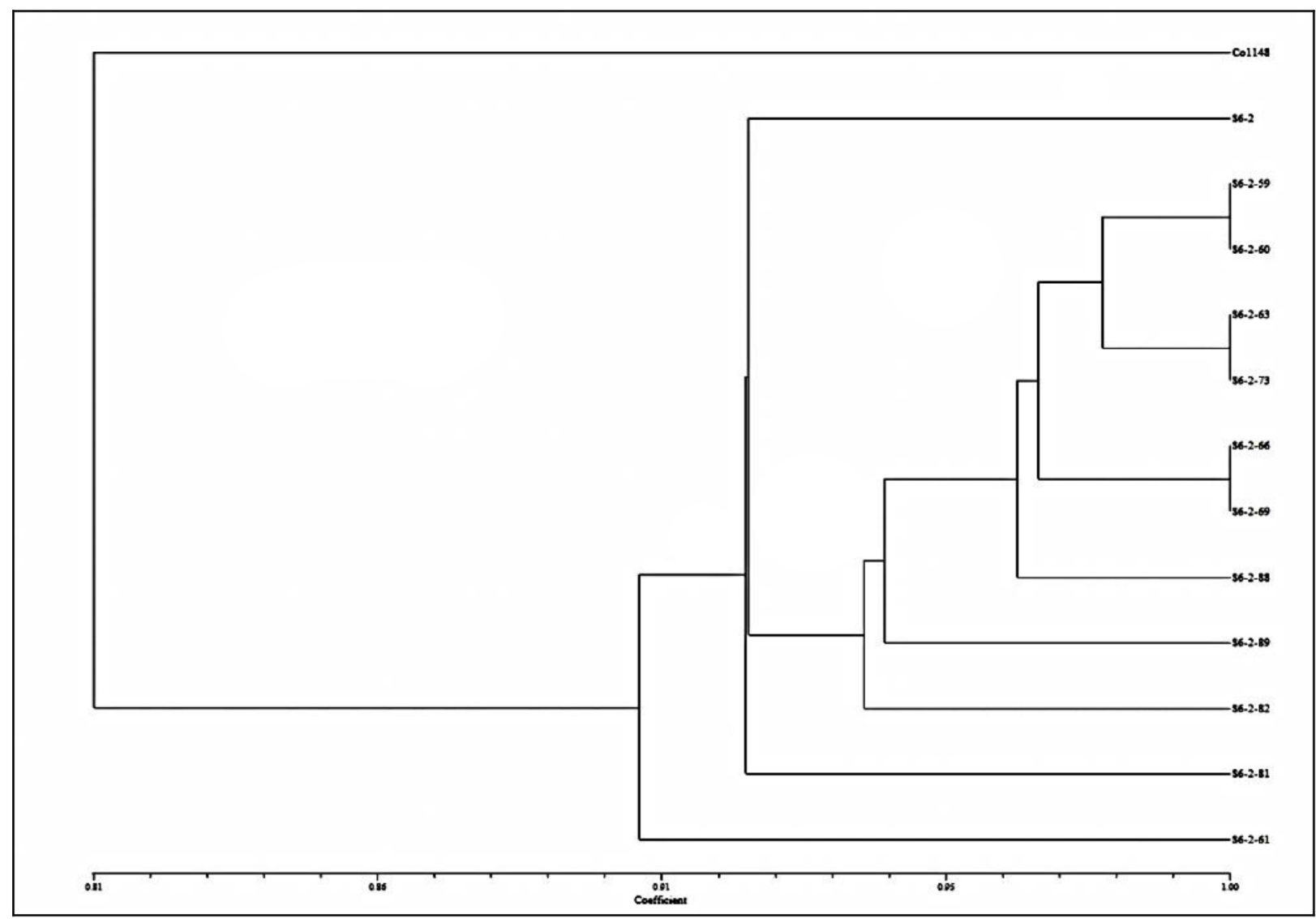

Fig.2. Dendrogram showing genetic similarity among advanced generation inbreds of Co 1148

$\mathrm{S}_{6}$ for cane thickness and 99008-113 and 9900891 in $\mathrm{S}_{1}$ and $775-\mathrm{S}_{2}-12$ in $\mathrm{S}_{2} 1148-13-11-2-237$ in $\mathrm{S}_{6}$ and 1148- $\mathrm{S}_{4}-242-7-121$ in $\mathrm{S}_{7}$ for HR Brix were identified to produce relatively uniform progenies for the above traits. The earlier generation inbred $775-\mathrm{S}_{2}-5$ with least variation for CT and HR Brix and the later generation inbred 1148-13-112-237 for NMC and HR Brix may considered for further selfing and developing inbreds which may be further utilized in hybridization to have homogenous progenies.

Among the four advanced generation inbreeding individuals showing the least variation for the traits studied viz., 1148-13-11-2-237 (for NMC and HR Brix), 1148-13-11-252-247 (for NMC), 1148-13-11-2-237-29 (for CT ) and 1148-S242-7 (for CT and HR Brix) showed the lowest variation for the traits studied. Two parents viz.,
1148-13-11-2-252-247 and 1148-13-11-2-237-29 showed higher variation in their $\mathrm{S}_{7}$ progenies for any one of the traits studied. Among the remaining two inbreds, $\mathrm{S}_{7}$ progenies of 1148-13-11-21-237 with sufficient number of individuals have been taken for molecular analysis of homozygosity. The molecular analyses of parents and inbred derivatives have shown a higher level of genetic similarity of inbreds in comparison to the respective parents (Plate 1 and Fig 2). Hemaprabha et al. (2000) also identified genotypes which showed higher levels of genetic similarity among the selfed progenies explicating the potential of some parents in giving a near homozygous population with limited selfing.

From the molecular analysis of $\mathrm{S}_{7}$ progenies, it is revealed that $\mathrm{S}_{6}-2-59$ and $\mathrm{S}_{6}-2-60, \mathrm{~S}_{6}-2-63$ and $\mathrm{S}_{6}-$ 2-73 and $S_{6}-2-66$ and $S_{6}-2-69$ were highly similar 
to each other while other inbreds viz., $\mathrm{S}_{6}-2-88$, $\mathrm{S}_{6}-2-89, \mathrm{~S}_{6}-2-82, \mathrm{~S}_{6}-2-81$ and $\mathrm{S}_{6}-2-61$ formed distinguished cluster indicating heterozygosity among the inbreeding individuals in the population. Similar report on similarity between inbred lines in maize was reported by Shehata et al. (2009). Relatively homozygous individuals at $\mathrm{S}_{5}$ to $\mathrm{S}_{7}$ generation of selfing identified in the study may be further selfed to get homozygous individuals or can be utilized directly in the crossing programme as donor parents to assess the combining ability and in identification of good combiners for hybrid seed production technology in sugarcane.

\section{Transgressive segregation on selfing in sugarcane}

The progeny mean and parental mean and the level of inbreeding depression (DE) and transgressive segregation (TS) in different generations of selfing is given in the Table 3. The parental mean and population mean were found the same for 0304-127 and its progenies for NMC, 99008-113 and its progenies for cane thickness in $S_{2}$ and 775-45-406 and its progenies for HR Brix in $\mathrm{S}_{3}$ generation. More number of transgressive segregants were obtained in Co 775, MS 68/47 and Co 0112 for NMC, in Co 99008, MS 68/47 and Co 0112 for HR brix and in MS 68/47 and Co 0112 for cane thickness. Among the 86 inbreds of Co 775, 20 had high number of NMC than the parent. Similarly, eight of Co 0112, five of MS 68/47, three each of Co 99008, CoM 0265 and two each of Co 94012, Co 95012 and Co 0402 were found to have better NMC than their respective parents. Four inbreds of Co 775, two inbreds of Co 99008 and one each of Co 0304 and MS 68/47 recorded significantly higher HR Brix than their parents (Data not shown). Similar observation in some of the selfed families of SP 88-754 and SP 84-202 were reported by Ferreira et al. (2005).

\section{Inbreeding depression (IBD) on selfing in sugarcane}

Inbreeding has been described as an extreme form of genetic assortative mating (Allard, 1960) and allogamous species are expected to have higher level of IBD. However it was demonstrated that selfing in sugarcane results in loss of vigour but not always (Stevenson, 1959). All the parents exhibited IBD for cane thickness and HR Brix and not for NMC in $\mathrm{S}_{1}$. The IBD for NMC varied from 2.00 (Co 2000-10) to $14.87 \%$ (Co 0304) in $\mathrm{S}_{1}$ and no IBD was observed among the $\mathrm{S}_{1}$ progenies of Co 775, Co 99008 and Co 0112. However, in $\mathrm{S}_{2}$ other than 775-22, all the families exhibited IBD that ranged from $1.50(775-45)$ to $61.47 \%$ (775-27). Though IBD was observed in few $S_{1}$ families and all the families in $\mathrm{S}_{2}$ except 775-22, the inbreeding depression for NMC was inhibited in such a manner that no inbreeding depression was observed for NMC at $\mathrm{S}_{3}$ generation of selfed populations of Co 775 and MS 68/47. Inbreeding in general is due to loss of favourable heterozygote combinations and IBD effect on a trait depends on the proportion of directional dominance in the trait. More number of transgressive segregants was observed for NMC which suggests further selfing to achieve homozygosity in this trait. This may be due to the fact that life history traits usually show less IBD since these characters were preferred over other traits during the selection or evolution process (Wright et al. 2007).

IBD for cane thickness varied from 0.73 (Co 200010) to 28.92 (Co 99008) in $\mathrm{S}_{1}$ and 3.75 (68/473) to 20.7 (0304-127) in $S_{2}$ and more number of families showed IBD for cane thickness (14). Silva and Goncalves (2011) also had the opinion that selfing resulted in reduction of average stalk diameter while studying the 26 parental clones from Brazil. Further less number of transgressive segregation in cane thickness may possibly be caused by the low frequencies of favourable 
Table 3. Inbreeding depression and transgressive segregation in $S_{1}, S_{2}$ and $S_{3}$ inbred populations

\begin{tabular}{lllllllllll}
\hline & \multicolumn{4}{c}{$\begin{array}{c}\text { Number of millable } \\
\text { canes }\end{array}$} & \multicolumn{3}{c}{ Cane thickness } & \multicolumn{3}{c}{ HR brix } \\
\hline Generation & Genotype & ProM & PM & IBD (\%) & ProM & PM & IBD (\%) & ProM & PM & IBD (\%) \\
\hline & Co 775 & 14.47 & 13.67 & Negative & 2.40 & 2.97 & 19.19 & 18.4 & 20.67 & 10.98 \\
& Co 99008 & 19.33 & 15.92 & Negative & 2.04 & 2.87 & 28.92 & 18.56 & 21.53 & 13.79 \\
S1 & C0 0304 & 13.34 & 15.67 & 14.87 & 2.70 & 3.23 & 16.41 & 20.06 & 21.53 & 6.83 \\
& Co 2000-10 & 14.70 & 15.00 & 2.00 & 2.71 & 2.73 & 0.73 & 17.11 & 17.33 & 1.27 \\
& Ms 68/47 & 13.00 & 13.52 & 3.85 & 2.97 & 3.00 & 1.00 & 14.12 & 16.87 & 16.30 \\
& Co 0112 & 15.52 & 15.33 & Negative & 2.60 & 2.65 & 1.89 & 15.61 & 20 & 21.95 \\
\hline & $775-21$ & 7.43 & 13.00 & 42.85 & 2.73 & 2.6 & Negative & 20.38 & 20.00 & Negative \\
& $775-22$ & 11.35 & 8.00 & Negative & 2.68 & 2.3 & Negative & 21.31 & 17.80 & Negative \\
& $775-27$ & 6.55 & 17.00 & 61.47 & 2.45 & 2.7 & 9.26 & 19.91 & 23.60 & 15.64 \\
S2 & $775-28$ & 8.00 & 10.00 & 20.00 & 2.48 & 2.6 & 4.62 & 21.03 & 21.00 & Negative \\
& $775-45$ & 7.88 & 8.00 & 1.50 & 2.55 & 2.8 & 8.93 & 21.76 & 20.80 & Negative \\
& $99008-91$ & 10.00 & 14.00 & 28.57 & 2.27 & 2.8 & 18.93 & 22.71 & 24.00 & 5.38 \\
& $99008-113$ & 9.35 & 11.00 & 15.00 & 2.3 & 2.3 & 0.00 & 22.69 & 23.00 & 1.348 \\
& $0304-127$ & 7.00 & 7.00 & 0.00 & 2.38 & 3.0 & 20.7 & 22.06 & 23.00 & 4.09 \\
& $68 / 47-3$ & 6.68 & 8.00 & 16.50 & 2.31 & 2.4 & 3.75 & 21.7 & 21.00 & Negative \\
\hline S3 & $775-45-406$ & 18.0 & 17.00 & Negative & 2.50 & 2.4 & Negative & 20.20 & 20.20 & 0.0 \\
& $775-27-311$ & 20.2 & 16.00 & Negative & 2.40 & 2.6 & 7.69 & 18.80 & 18.20 & Negative \\
& $68 / 47-3-12$ & 16.2 & 16.00 & Negative & 2.40 & 2.3 & Negative & 19.80 & 20.80 & 4.80 \\
\hline
\end{tabular}

$\mathrm{IBD}=$ Inbreeding depression; ProM= Progeny mean ; $\mathrm{PM}=$ Parental mean; the word 'Negative' indicate transgressive segregants in positive direction

alleles for these traits. Clones with higher parental mean had severe IBD for cane thickness. However the most promising results were obtained in 77521 with higher parental mean and produced lesser level IBD for cane thickness. These results were in agreement with Cassalet et al. (1996) and Silva and Goncalves (2011) and the effect may be due to retention of the superiority of parents in successive generations of selfing by some of inbreeding individuals.

IBD for H.R brix varied from 1.27 (Co 2000-10) to 21.95 (Co 0112) in $\mathrm{S}_{1}$ and 1.35 (99008-113) to 15.64 (775-27) in $\mathrm{S}_{2}$. In $\mathrm{S}_{2}$ generation, $\mathrm{HR}$ brix was the trait which showed very less IBD than other traits. The IBD for H.R brix was reduced from maximum of $21.95 \%$ in $\mathrm{S}_{1}$ to $4.80 \%$ in $\mathrm{S}_{3}$.
Hogarth (1980) and Ferreira et al. (2005) also observed that brix was the less affected trait by the IBD. Some of the clones with higher parental mean had less IBD for HR Brix and cane thickness due to inheritance of excellent agronomic traits of the parents by these inbreds. Hogarth (1980) who analyzed some diallel crossings stated that the trait brix was not affected by IBD indicating that the genetic variance for brix is additive.

\section{Conclusion}

Transgressive segregants identified in the earlier generation of inbreeding may be utilized to develop trait specific inbreds by repeated selfing guided by molecular profiling of the progenies for generation advancement and selecting for positive extremities for the traits of breeding importance. 
Inbreds with higher level of homozygosity in the later generation of selfings viz., $\mathrm{S}_{6}-2-59$ and $\mathrm{S}_{6}-2-60, \mathrm{~S}_{6}-2-63$ and $\mathrm{S}_{6}-2-73$ and $\mathrm{S}_{6}-2-66$ and $\mathrm{S}_{6}-$ 2-69 of Co 1148 developed in this study may be utilized for hybrid seed production in sugarcane after assessing their combining ability, breeding values and seed setting percentage in the inbred cross combinations. This study also revealed the fact that it is possible to develop inbred population with high sucrose and also identify superior inbred donors for improvement of yield traits viz., NMC and $\mathrm{CT}$ in future breeding programmes.

\section{Acknowledgements}

The authors are grateful to the Director, ICARSugarcane Breeding Institute, Coimbatore for the encouragement and providing facilities to conduct the experiments

\section{References}

Allard RW (1960) Principles of Plant Breeding. John Willey and Sons Inc., New York.

Babu CN, Ethirajan AS (1962) A note on use of Saccharum spontaneum in sugar cane. Proceedings of the XI International Society of Sugarcane Technologists Congress, pp 464-469.

Cassalett C, Viveros CA, Pizza LR (1996) Selfpollination in sugarcane hybrids, Saccharum spp. Proceedings of the XXII International Society of Sugarcane Technologists Congress 1996. Carthagene p 312-315.

Doyle JJ, Doyle LJ, Doyle FJ (1987) A rapid DNA isolation procedure for small quantities of fresh leaf tissue. Phytochemical Bulletin 19 (1): 11-15.

Durai AA, Hemaprabha G, Ravinder Kumar, Mohanraj K (2012) Effect of selfing on important economic traits in sugarcane (Saccharum $s p$ ). Journal of Sugarcane Research 2 (2): 29-33.
Durai AA, Hemaprabha G (2016) Heterosis and Combining ability of sugarcane inbreds for early stage selection traits. Journal of Sugarcane Research 6 (1): 27-34.

Ethirajan SA, Santhakumariamma PN, Velayutham N (1978) Studies on successive inbred generations of selected sugarcane cultivars. Proceedings of the XVI International Society of Sugarcane Technologists Congress 1978, Sao Paulo, pp 269-273.

Ferreira FM, Barbosa MHP, Castra RD De, Peternelli LA, Cruz CD ( 2005) Effects of inbreeding on the selection of sugar cane clones. Crop Breeding and Applied Biotechnology. 5 (2): 174-182.

Hemaprabha G, Natarajan US, Balasundaram N, Subramonian N (2000) Quantification of genetic similarity among inbred progenies and identification of desirable parents for population development in sugarcane (Saccharum spp.) through isozyme analysis. Sugar Cane International 2000 No. September pp.16-18.

Hemaprabha G, Natarajan US, Balasundaram N (2003) Breeding behavior for juice quality through selfing and progeny evaluation in hybrid clones and inbred derivatives of sugarcane (Saccharum spp.) Sugar Tech 5 (3): 177-200.

Hemaprabha G, Singh NK (2007) Evaluation of parental value of selfs in sugarcane (Saccharum spp.) breeding. The Indian Journal of Genetics and Plant Breeding 67 (3): 248-253.

Hogarth DM (1980) The effect of accidental selfing on the analysis of a diallel crosses with sugarcane. Euphytica 29: 737-746.

Jaccard P (1908) Nouvelles researches sur la 
distribution florale. Bulletin de la Société vaudoise des sciences naturelles., 44:223270 .

Mettler LE, Gregg TGC (1973) Genetica de Populacoes Poligono / EDUSP, Sau Paula, $262 p$.

Nei M, Li WH (1979) Mathematical model for studying genetic variation in terms of restriction endonucleases. Proceedings of the National Academy of Sciences, 76 (10): 5269-5273.

Panje RL, Ethirajan AS (1959) Studies on Saccharum spontaneum - Preliminary studies in inbreeding. Proceedings of the $\mathrm{X}$ International Society of Sugar Cane Technologists Congress.

Ram Bakshi, Hemaprabha G, Premachandran MN (2015) Sugarcane cultivation through true seed-A historic step towards changing the mode of transportation of sugarcane seed from truck to pocket. SBI NEWS, 35; $1-2$.

Roach BT, Daniels J (1987) A review of the origin and improvement of sugarcane. In: Copersucar Intern. Sugar Cane Breeding Workshop, Brazil. pp 1-31.

Shanthi RM, Alarmelu S (2011) Parental stocks for early high sugar content through simple recurrent selection. SBI News, 31 (4): 2-3

Shehata Afaf I, Al-Ghethar Haila A, Al Homaidan Ali A (2009) Application of simple sequence repeat (SSR) markers for molecular diversity and heterozygosity analysis in maize inbred lines. Saudi Journal of Biological Sciences, 16: 57-62.

Silva M de, Goncalves, P.De S (2011) Inbreeding in sugarcane varieties. Ciencia Rural 41(4): 580-586.

Stevenson GC (1953) The use of selfing and inbreeding with sugarcane. Proceedings of the VIII International Society of Sugar Cane Technologists, 1954, British West Indies, 509-520.

Stevenson GC (1959) Inbreeding with sugar Cane in Barbados. Proceedings of the $\mathrm{X}$ International Society of Sugarcane Technologists Congress 1960, Hawaii, pp 670-682.

Stevenson GC (1965) Genetics and Breeding of Sugarcane. Longmans, Green and Co. Ltd., London pp. xi $+248 p p$.

Wright LI, Tregenza T, Hosken DJ (2007) Inbreeding, inbreeding depression and extinction Conservation Genetics DOI 10.1007/s10592-007-9405-0 